\title{
Analysis and Predictions of Seasonal Affected Weather Variables of Bangladesh: SARIMA Models vs. Traditional Models
}

\author{
Md. Salauddin Khan ${ }^{1}$, Masudul Islam ${ }^{1,2}$, Sajal Adhikary ${ }^{1}$, Md. Murad Hossain ${ }^{3}$, Sohani Afroja ${ }^{1}$ \\ ${ }^{1}$ Statistics Discipline, Khulna University, Khulna, Bangladesh \\ ${ }^{2}$ Department of Mathematical Science, Ball State University, Muncie, Indiana, USA \\ ${ }^{3}$ Department of Statistics, Bangabandhu Sheikh Mujibur Rahman Science and Technology University, Gopalganj, \\ Bangladesh \\ Correspondence: Masudul Islam, Department of Mathematical Science, Ball State University, Muncie, Indiana, \\ USA. E-mail: mislam4@bsu.edu
}

Received: August 11, 2018

Accepted: October 26, $2018 \quad$ Online Published: November 12, 2018

doi:10.5539/ijbm.v13n12p70

URL: https://doi.org/10.5539/ijbm.v13n12p70

\begin{abstract}
Bangladesh is a semi-tropical country, categorized by widespread seasonal disparities in rainfall, temperature, and humidity. Seasonality has been an input aspect of time series modeling when taking into account weather variables. In terms of multiple features of the weather variables i.e. randomness, cyclical variation and trend, time series methods etc. ARIMA can be a superior preference but, weather variables are affected by seasonality. Thinking about the grimy meadow, this paper presents Seasonal Auto-regressive Moving Average (SARIMA) model that takes seasonal and cyclical variation over the years. This study also aims to compare traditional methods like Single Exponential Method, Double Exponential Method, and Holt Winter Method with the SARIMA model. Time series plots, month plots, and B-B plots are used for identifying seasonal effect clearly. For seasonal stationary checking, Canova Hansen Stationary test has been utilized. Then, the order of the variables is identified, ACF and PACF have been checked and estimated preeminent order for these variables by AIC and Log-likelihood. Finally, Single Exponential Method, Double Exponential Method, and Holt Winter Method are introduced for comparing and forecasting. The proposed models SARIMA $(0,0,0)(1,0,3) 12$, $\operatorname{SARIMA}(0,0,0)(1,0,1) 12, \operatorname{SARIMA}(0,0,0)(1,0,2) 12$ and $\operatorname{SARIMA}(0,0,0)(1,0,1) 12$ for maximum and minimum temperature, rainfall and humidity on the basis of Akaike Information Criteria and Log likelihood have been captured most seasonality of the data. Comparing them with traditional methods, traditional methods give a better result than the acquired model based on error measurement. So, traditional methods give a better estimate than the SARIMA models for selected weather variables, with lower mean square error, RMSE, MAE and MASE.
\end{abstract}

Keywords: SARIMA, single exponential method, holt-winters' method, chi-square test, weather variables

\section{Introduction}

Forecasting is a procedure in managing to support decision making as well as the process of estimation in unidentified future situations (Khan, Islam, Kabir, \& Ali, 2016). Bangladesh, extremely vulnerable to natural adversities because of its terrestrial position, evenly and low-lying land, densely populated, poverty, high illiteracy, deficiency of institutional set up etc., is one of the leading deltas in the world. Also, Bangladesh is typically one of the most susceptible countries to natural calamities around the globe (Chatfield, 2003). The area of Bangladesh is consisting of 147570 sq. km that are typically floodplains (nearly 80\%) leaving the majority of the country inclined to flood throughout the rainy season. Furthermore, climate alteration of the country mainly depends on high temperature, rising sea level, cyclones, and storm flow, salinity interruption, deep monsoon downpours etc. that affect the total financial condition (Chatfield, 2003). So, the climate can be categorized by three seasonal variations like burning summer, shrinking winter and average to intense rains in rainy time in Bangladesh. Even with the latest strides towards attaining sustainable development, Bangladesh's potential to sustain its development is faced with noteworthy challenges posed by climate alteration (Ahmed, \& Haque, 2002). That is why utmost weights are specified for variation to climate shift by identifying its susceptibility in terms of population and sectors at risk and it is potential. For this reason, Bangladesh Government has taken streamline actions towards helping to rework climate alteration and has set up the climate change cell under the 
guidance of the environment and forest ministry through the eye on crucial points of climate alteration problems. Moreover, Comprehensive Disaster Management and the UNDP supervised the activities of CCC activities. The climate change cell has made an excellent effort to the make readers aware about the dynamics of climate change and feebleness in Bangladesh by accessible on climate change documents to assess and produce the current knowledge. Also, a project was specially made on which the authors planned a study to combine all the pertinent findings accessible in the presently existing literature, so it helps in perceptive of climate change and classifies paths of action by various factors involved in the national expansion progressions (Ahmed, 2006).

Since Bangladesh is a climate exaggerated state, the authorities of the country must take a right decision about the future. Forecasting techniques akin to BJ method can facilitate us to predict the prospect climate change to assist the Bangladesh authorities. The BJ model has urged ARIMA model for forecasting among other methods (Wilks, 1938). Formally, Klein et al. (1970), Glahn \& Lowry (1972) and Pankratz (1983) applied simple quantitative precipitation forecasting methods where they used changing patterns and variability in rainfall that may be associated with global warming due lost their edge [26,18,23]. Borlando (1996) exploited ARIMA models to forecast the amounts gained and hourly precipitation in the time of their fall to evaluate the rain data (Kibunja, Kihoro, Orwa, \& Yodah, 2014). Yusof and Kane (2012) examined seasonality of rainfall prediction using the SARIMA model for Golastan province (Wilks, 1938). Permanasari (2013) introduced SARIMA for forecasting number of complaint incidence in human (Ahmed, \& Haque, 2002). Also, the ARIMA proffer an excellent process for producing the magnitude of any variables (Manoj Kumar, 2009). Lloret (2000) pioneered in fishery ARIMA models to forecast fishery landing in the Hellenic sea waters when lacking organized biological time series datasets from advisory erratic (Josep Lloret, 2000). Fang (1998) combined two methods, time-series and fuzzy regression in financial forecasting, to extend the fuzzy ARIMA model pedestal upon the works (Tseng, Tzeng, Yu, \& Yuan, 1998). Ediger (2007) forecasted preliminary energy claim on fossil fuel using ARIMA and SARIMA model (Volkan \& Ediger, 2007). Wood (1996) utilized ARIMA and Neural Network to project United Stated America Capital Market Index (Douglas Wood, 1996). The foremost aims of this study are: firstly, to analyze the special distinctiveness of the time series model all the way through diverse tests. Secondly, to build up a pertinent time series models for forecasting of the selected weather variables. Thirdly, to compare forecasting accuracy in different forecasting models through accuracy measurements. Finally, to recognize weather patterns in Bangladesh.

\section{Methods and Materials}

\subsection{Data Collection and Computation}

In this paper, secondary data are used for investigation and ultimate encroachment. Selected components of weather data such as maximum temperature, minimum temperature, rainfall and humidity, have been collected from the websites of Bangladesh Bureau of Statistics and Bangladesh Metrological Department (Bangladesh Bureau of Statistics, 2014). Analytical solutions are perpetrated through R-3.3.2 and Minitab-15.

\subsection{Graphical Analysis of Time Series Data}

The primary important thing is the exploration and visualization the data through graphs. Basic features, patterns and unusual observations of the data are most easily seen through graphs. Graphs also suggest possible explanations for some of the changes in the data. The initial footstep of any time series is to figure out the data that evidence the possible nature of the time series or express trend, seasonal or cyclical variations etc (Makridakis, Wheelwright, \& Hyndman, 1998). This suggests whether the time series is nonstationary or not (Fomby, 2008).

\subsection{Monthly Plot of Time Series}

Seasonal subseries designs are a diagrammed tool to imaging and identifying seasonality in a time series by removing the seasons from a time series into a subseries by monthlies (Cleveland, 1995; Maindonald, \& Braun, 2010). A seasonal subseries plot allows to see clearly the seasonal shape and shows the fluctuations in seasonality over time to allow detecting changes between different seasons, changes within a specific season over time. However, this plot is the only useful tool in many cases when the period of the seasonality is already identified (Glahn, \& Lowry, 1972).

\subsection{Buys Ballot Plot of Time Series}

Diagnosing the presence or absence of seasonal effects in time series, Buys Ballot plots play so useful contributions. "the Seasons-By Year" plot, "the Seasonal Trends" plot and "the Seasonal Averages" plot is of them. Separately, these plots are observed and compare with non-seasonal time series. The plots and have found to be so 
idiosyncratic across the data sets. These shapes assist us properly accounted for time series modeling from side to side identifying the presence of seasonality (Cleveland, 1995).

\subsection{Auto-Correlation Function}

The role of ACF is very important at the identification of time series process. It processes the track and strong point of statistical affiliation between well-organized pairs of observation in a data series. The auto-correlation function at lag $n$, indicated by $\rho_{n}$, is sharped as:

$$
\rho_{n}=\frac{\gamma_{n}}{\gamma_{0}}=\text { Covariance of } \mathrm{k} \text { variance }
$$

The graph $\rho_{n}$ against lagn is known as the population Correlogram [24].

\subsection{Canova and Hansen Seasonality Test}

Hansen and Canova (1995) recommended that the seasonal shape is stable for a null hypothesis. Under this hypothesis, test statistic can be expressed using seasonal dummies or seasonal cycles. The earlier permits us to identify seasons such as months or quarters that are not constant. And the concluding tests the constancy of seasonal cycles (e.g. cycles in quarterly data). It is an interesting tool that is used as a complement to the more common unit root tests. Moreover, it is very helpful to recognize the seasons that cause the instability in the seasonal shape to discover an explanation for evolving patterns, for example, changes in socio-economic phenomena (George, Jenkins, Reinsel, \& Ljung, 2015).
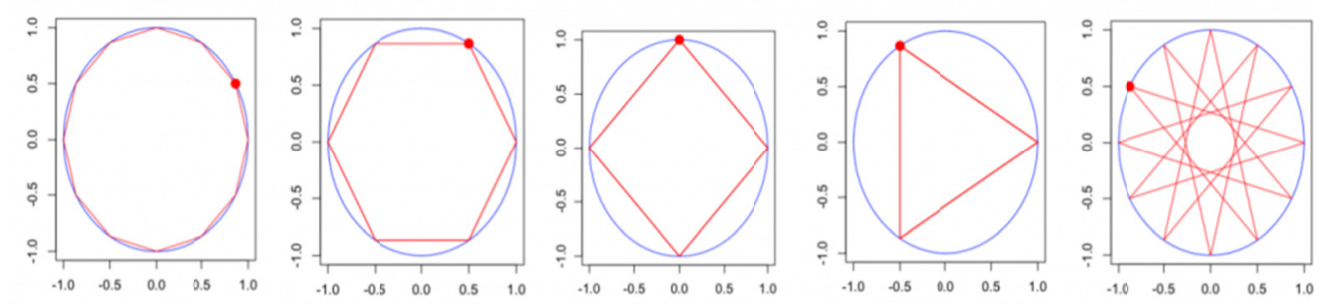

Figure 1. Graphical representation of Canova-Hansen test

Here we can have 1 cycle per year (on 12 months), 2 cycles per year (on 6 months), 3 cycles per year (on 4 months), 4 cycles per year (on 3 months) and even 6 cycles per year (on 2 months). This will depend on the argument of the root, with respectively. For monthly data the frequencies are:

$$
\left\{\frac{\pi}{6}, \frac{\pi}{3}, \frac{\pi}{2}, \frac{2 \pi}{3}, \frac{5 \pi}{6}, \pi\right\}
$$

The test statistic for Canova-Hansen test is: $L=\frac{1}{T^{2}} \operatorname{tr}\left(\left(A^{\prime} \widehat{\Omega}^{f} A\right)^{-1} A \sum_{t=1}^{T} \widehat{F}_{t} \widehat{F}^{\prime}{ }_{t} A\right)$.

Where, $\widehat{F}_{t}=\sum_{j=1}^{t} f_{j} \hat{\varepsilon}_{j} \widehat{\Omega}^{f}$ is a consistent estimate of the covariance matrix of $f_{t} \varepsilon_{j}$.

$\widehat{\Omega}^{f}=\sum_{k=-m}^{k=m} W\left(\frac{k}{m}\right) \frac{1}{T} \sum_{t=1}^{T} f_{t+k} \hat{\varepsilon}_{t+k} f^{\prime}{ }_{t} \hat{\varepsilon}_{t}$ and $W($.$) is a kernel, a positive semi-definite matrix. Once$ performing stability of the $j^{\text {th }}$ intercept. It can be reached by taking $A$ to be the unit vector with a 1 in the $j^{t h}$ element and zeros elsewhere, $f^{\prime}{ }_{j t}$ is the deterministic cyclical process at the seasonal frequency $\theta_{j}=\frac{2 \pi j}{S} ; j=$

$1,2, \ldots, S$; which defining $S^{*}$ as $\frac{S}{2}-1$. If $\mathrm{S}$ is even and $(S-1) / 2$; if $S$ is odd may be distinct as:

$f^{\prime}{ }_{j t}=\left\{\left(\cos \left(\theta_{j} t\right), \sin \left(\theta_{j} t\right)\right) ; j=1 \cdots S^{*}, f^{\prime}{ }_{j t}=\left\{\left(\cos \left(\theta_{j} t\right)\right) ; j=S / 2\right.\right.$ (only for even).

Where, $\mathrm{S}$ is the number of the seasonal periods (Diaz-Emparanza, \& Moral, 2014).

\subsection{Model Selection Criterion}


Model selection is an imperative fragment of any statistical analysis. This paper considers different tests such as Akaike information criterion $(A I C=(2 k-2) /(\ln (L)))$ and maximum likelihood function (minimize $-\log$ Likelihood $=-\log L(\beta)[3,31]$ for model selection.

\subsection{The Methods for Prediction}

Very often, management makes a plan for decision making and planning to help the administration in order to take the precise accurate decision. So, forecasting accuracy is very much required in the decision-making process. In some cases, the prediction may be peripheral to the decision being made and so a low-level accuracy may be adequate even though the decision may be an important one. So, determine in progress the least level of forecasting accuracy will be satisfactory in any situation (Wichern, \& Hanke, 2014).

\subsubsection{Seasonal Autoregressive Integrated Moving Average (SARIMA)}

SARIMA has built as the non-seasonal fragment, AR factor, MA factor, and/or order of difference. Abundant of lags such as the number of periods in a season occurs in the seasonal portion of the model and all these factors operate across these multiples of lag s. A SARIMA model is categorized as an $\operatorname{ARIMA}(p, d, q)(P, D, Q)_{\mathrm{m}}$ model,

$$
\begin{aligned}
& \text { ARIMA }(p, d, q)(P, D, Q)_{m} \\
& \left\{\begin{array}{c}
\text { Non-seasonal part } \\
\text { Seasonal part of }
\end{array}\right\}
\end{aligned}
$$

Where, $\mathrm{P}$ is the quantity of SAR terms, $\mathrm{D}$ is the number of periodic differences, and $\mathrm{Q}$ is the quantity of SMA terms. If the seasonal pattern is both strong and stable over time, then one can probably use a seasonal difference regardless of whether he/she uses a non-seasonal difference, since it will avoid from dying out in the enduring estimates. Also, $m$ is the quantity of periods per season (Chatfield, 2003).

\subsubsection{Single Exponential Smoothing Method}

Single exponential smoothing usages an exponentially weighted average of entire past values of the series to analyze the smoothed value at the individual era. The furthermost observation takes the largest weight $\alpha$ (where $0<\alpha<l$ ), the following latest observation obtains small weight $\alpha(1-\alpha)$, the observation two-time periods in the former even less weight, $\alpha(1-\alpha)^{2}$ and so forth (Newbold, Carlson, $\&$ Thorne, 2012).

\subsubsection{Double Exponential Smoothing}

Double exponential smoothing works a level factor and trend element for each period. It practices two weight, or smoothing parameters, to reform the components at apiece. The double exponential smoothing equalities are:

$$
L_{t}=\alpha Y_{t}+(1-\alpha)\left(L_{t-1}+T_{t-1}\right)=g\left(L_{t}-L_{t-1}\right)+(1-g) T_{t-1} \text { and } t=L_{t-1}+T_{t-1} .
$$

where, $L_{t}$ is the time $t$ at level $L, \alpha$ is the weight for the level, $T_{t}$ is the time $\mathrm{t}$ with the trend, $g$ is the weight for the trend, $Y_{t}$ is the data value at time random, $t$ is the fitted value (Newbold, Carlson, \& Thorne, 2012).

\subsubsection{Holt-Winters' Method}

Winter's Method calculates energetic assessments for three modules: level, trend, and seasonal. While the level and seasonal components are multiplied together, Holt-Winters' model is multiplicative and when they are added tranquil, is addictive. So, two models are as below:

i) Additive model: $L_{t}=\alpha\left(Y_{t}-S_{t-p}\right)+(1-\alpha)\left[L_{t-1}+T_{t-1}\right]$

ii) Multiplicative model: $\quad L_{t}=\alpha\left(Y_{t} / S_{t-p}\right)+(1-\alpha)\left[L_{t-1}+T_{t-1}\right]$

where, $T_{t}=\gamma\left[L_{t}-L_{t-1}\right]+(1-\gamma) T_{t-1}, S_{t}=\delta\left(Y_{t} / L_{t}\right)+(1-\delta) S_{t-\mathrm{P}}$ and $\hat{Y}_{t}=\left(L_{t-1}+T_{t-1}\right)\left(\mathrm{S}_{\mathrm{t}-\mathrm{p}}\right)$ and $L_{t}$ is the level at time $t, a$ is the weight for the level, $T_{t}$ is the trend at time $\mathrm{t}, Y$ is the weight for the trend, $S_{t}$ is the seasonal component at timet, $\delta$ is the weight for the seasonal component, $\mathrm{p}$ is the seasonal period, $Y_{t}$ is the data value at time $t$ and $\hat{Y}_{t}$ is the fitted value, one-period-ahead forecast, at time $t$ (Newbold, Carlson, \& Thorne, 2012).

\subsection{Forecasting Accuracy Measurements}

Most of the forecasting methods process some functions on the average to differentiate and its forecast value. These differences concerning practical values and prognosis values are often mentioned as residuals. 
Table 1. Measures of forecasting accuracy

\begin{tabular}{lc}
\hline Accuracy measurements & Measuring equations \\
\hline Root mean square error (RMSE) & $R M S E=\sqrt{\frac{1}{n} \sum_{t=1}^{n}\left(Y_{t}-\hat{Y}_{t}\right)^{2}}$ \\
Mean absolute error (MAE) & $M A E=\frac{1}{n} \sum_{t=1}^{n}\left|Y_{t}-\hat{Y}_{t}\right|$ \\
Mean absolute scaled error (MASE) & $M A S E=\frac{\sum_{t=1}^{T}\left|e_{t}\right|}{\frac{T}{T-m} \sum_{t=m+1}^{T}\left|Y_{t}-Y_{t-m}\right|}$ \\
\hline
\end{tabular}

where, $Y_{t}$ is the actual value of forecast, $\hat{Y}_{t}$ is the predictor and $n$ is the different times for which the variable in an estimate, $e_{t}$ is the forecast error for a given period and $\mathrm{m}$ is the seasonal period (Yusof, \& Kane, 2013).

\section{Analysis and Results}

Changing weather varies with time shifting. Bangladesh's weather is not out of that jerky. So, weather portends rely on weather's variation and way of prediction. The following figures can give us an idea about the high and low temperature (in degree Celsius), rainfall (in $\mathrm{mm}$ ), humidity (in percentage) of Bangladesh of the last sixty years (1948 to 2012).
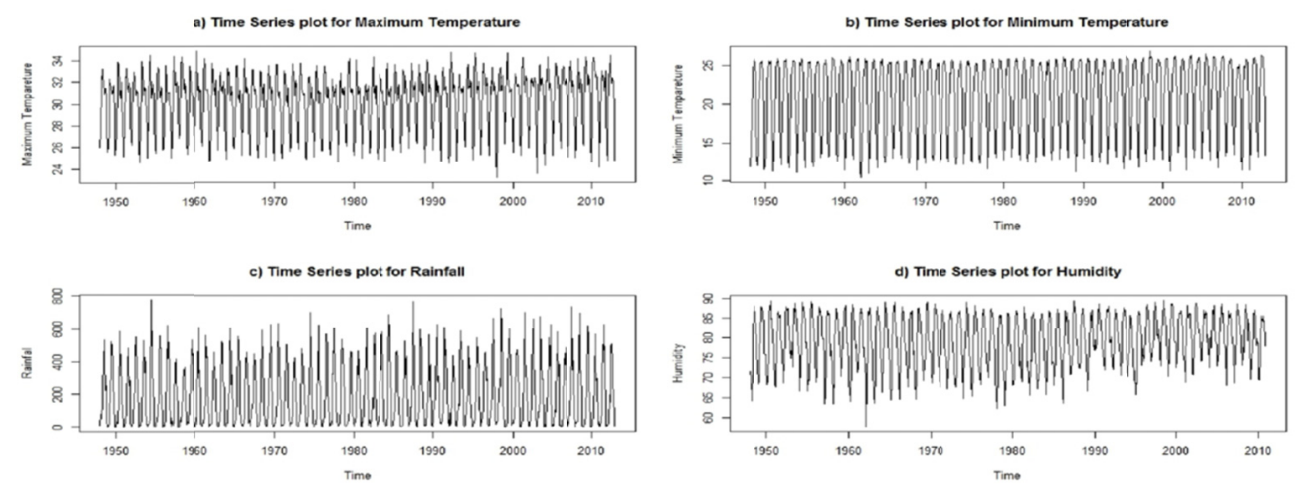

Figure 2. The time series plots for different selected variables in Bangladesh

In figure 2, it is observed that seasonality effects physically powerful within each year as well as brawny cyclical behavior with the period. Also, no noticeable trend effect detected over the period. So, month plots and B-B plots have been utilized for identifying seasonal effect clearly.
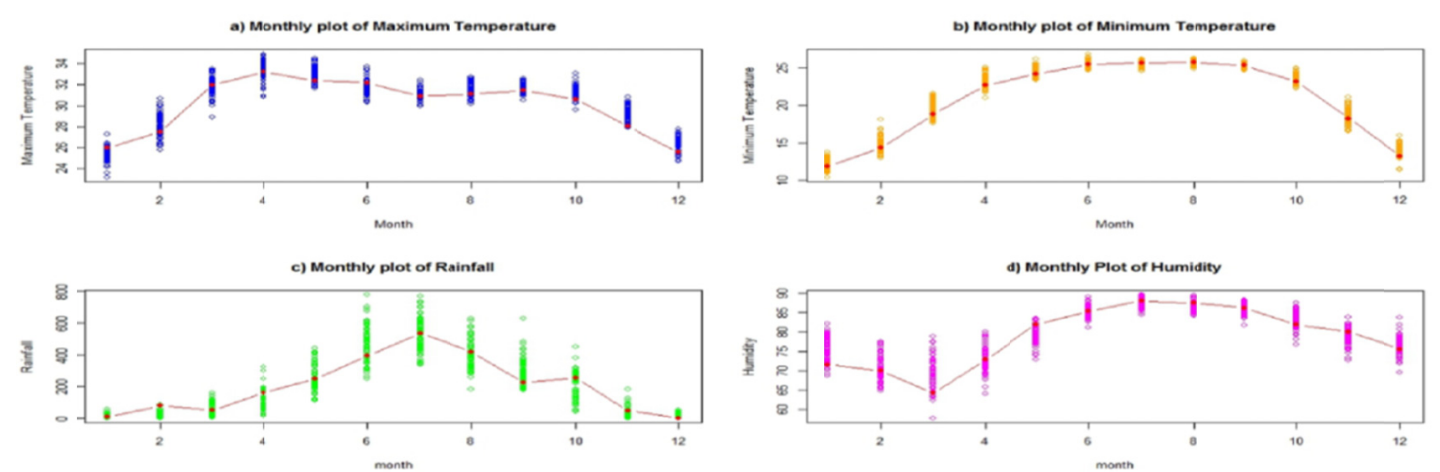

Figure 3. Monthly (seasonally or periodically return) time series plot for selected weather components 
The figure 3, middle contour signifies the mean values of each month of the related variables and the color bands exemplify weather components mold in different months in every year. The figure shows the shape of the different selected variables as 1 for January, 2 for February and 12 for December. Since, each variable gives an idea about these same patterns in each year which convey all the selected weather variables are affected with seasonality. Then it is also examined those variables through Buys-Ballot plot for more simplification.
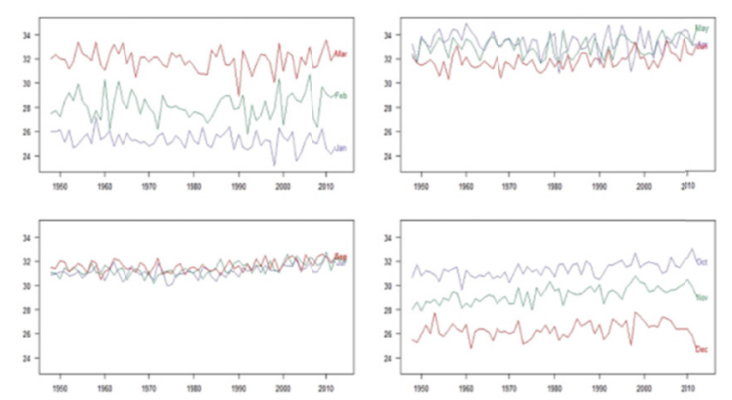

a) B-B plot for maximum temperature
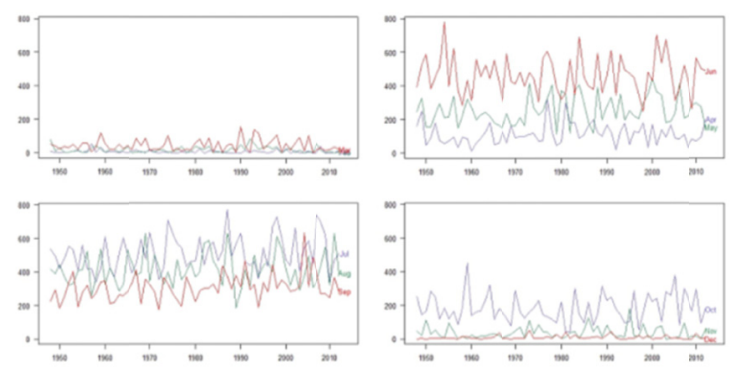

c) B-B plot for rainfall
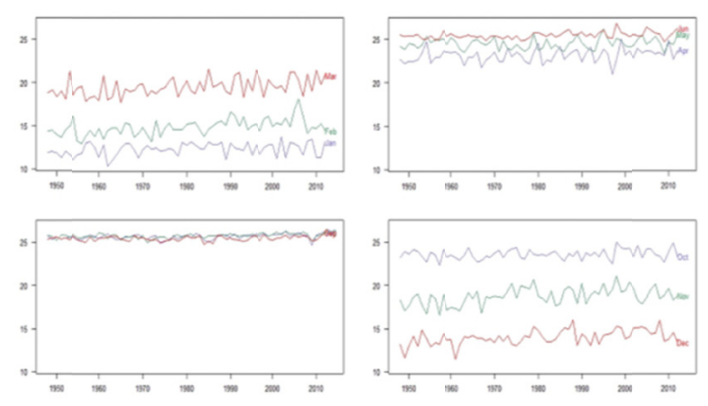

b) B-B plot for minimum temperature
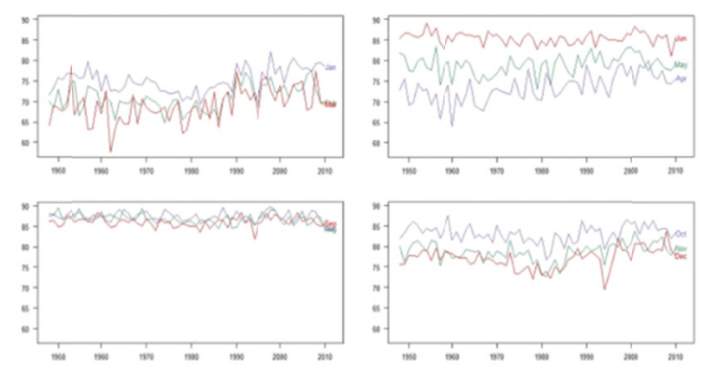

d) B-B plot for humidity

Figure 4. B-B plots for different selected weather variables in Bangladesh

The figure 4 shows the highest and lowest temperature, rainfall, humidity of Bangladesh in different years separately in a month with four parts and each part contains three months. In figure 4 shows that the differences of high and low temperature, rainfall and humidity in a month of each year are not so diverse. The maximum temperature of Bangladesh is in January $\left(26^{\circ} C\right)$, February $\left(28^{\circ} C\right)$, and July to September approximately similar $\left(31^{0} C\right)$. Also, the maximum temperature declines bit by bit from October to December. It is also monitored that the maximum temperature of January and December always low down in singular years and March, April and May always have towering temperature and for other months, the maximum temperature more or less identical pattern in singular years. Similarly, figure 4(b), minimum temperature of Bangladesh is in January $\left(11^{0} C\right)$, February $\left(14^{0} C\right)$, as well as July to September approximately equal $\left(25^{0} C\right)$. Also, the minimum temperature drops off slowly from October to December. For, figure 4(c), rainfall of Bangladesh is about $500 \mathrm{~mm}$ in June and $560 \mathrm{~mm}$ in July. Here, rainfall enlarges hurriedly from May to July and shrinks swiftly from August to December. A little bit rains on time December to March. Figure 4(d), humidity of Bangladesh is in January (76\%), February (70\%), July to September nearly unchanged, around 87\%. After that, humidity declines gradually from October to December. All figures, 4(a)-4(d), maximum and minimum temperature, rainfall, humidity of Bangladesh is seasonally affected. 


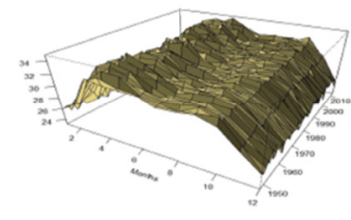

a) 3-D B-B plot for maximum temperature

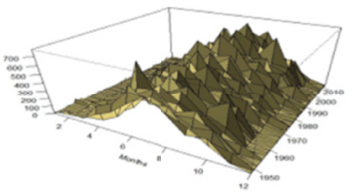

c) 3-D B-B plot for rainfall

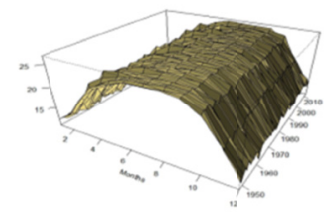

b) 3-D B-B plot for minimum temperature

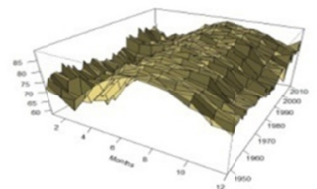

d) 3-D B-B plot for humidity

Figure 5. B-B (3-D) plot for different selected weather variables in Bangladesh

In figure 5, B-B (3-D) plot in each shape shows the change in the same pattern with respect to months all the years. So, all the selected weather variables of Bangladesh appeared hereby is seasonally affected. Now, we figure out auto-correlation function (figure 6), where ACF of those variables show an oscillation, indicative of a seasonal series. ACF shows peaks occur following at lags 12 months and subsequent to 24,36 and more. But the exception occurs for maximum temperature where January 1948 correlates with January 1949 and 24 months and subsequent months.
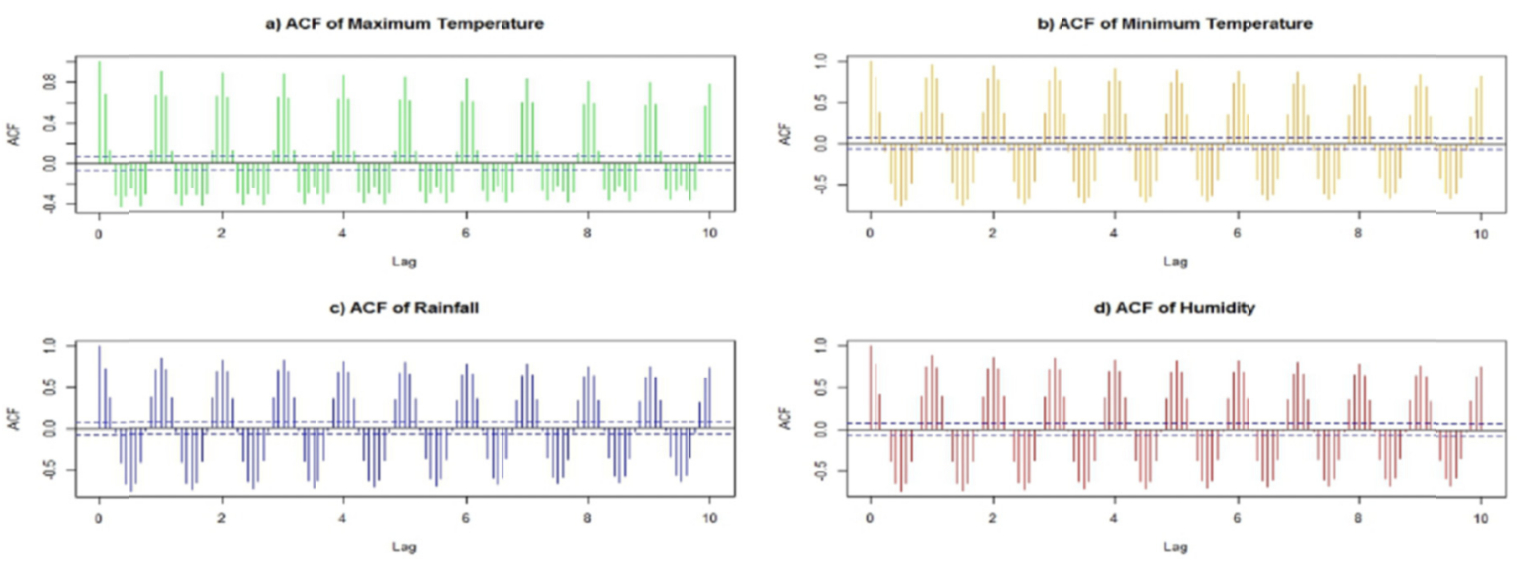

Figure 6. ACF plot for selected weather variables of Bangladesh

For seasonality stationary checking, it is exploited Canova Hansen stationary test. The CHS test satisfied the hypothesis that weather variables of Bangladesh are seasonally affected at $1 \%$ level. Now, the different SARIMA models, $\operatorname{SARIMA}(0,0,0)(1,0,3)_{12}, \operatorname{SARIMA}(0,0,0)(1,0,1)_{12}, \operatorname{SARIMA}(0,0,0)(1,0,2)_{12}$ and $\operatorname{SARIMA}(0,0,0)(1,0,1)_{12}$ via models are selected through selection criteria (AIC, Log-likelihood) for maximum temperature, minimum temperature, rainfall and humidity of Bangladesh as well as these models are used for forecasting among the other models. 
Table 2. The model selection criterions of the selected weather variables

\begin{tabular}{|c|c|c|c|c|c|c|c|c|}
\hline \multirow{2}{*}{$\begin{array}{l}\text { Variables } \downarrow \\
\text { Models }\end{array}$} & \multicolumn{2}{|c|}{ Maximum Temperature } & \multicolumn{2}{|c|}{ Minimum Temperature } & \multicolumn{2}{|l|}{ Rainfall } & \multicolumn{2}{|c|}{ Humidity } \\
\hline & AIC & Log-Likelihoo & AIC & Log-Likelihoo & AIC & Log-likelihoo & AIC & Log-likelihoo \\
\hline $\operatorname{SARIMA}(1,0,0)$ & 2166.1 & -1080.04 & 2102.1 & -1048.04 & 9373.7 & -4683.9 & 3722.4 & -1858.2 \\
\hline $\operatorname{SARIMA}(1,0,1)$ & 1733.2 & -862.59 & 1671.6 & -831.78 & 8777.6 & -4385.78 & 3425.7 & -1708.5 \\
\hline $\operatorname{SARIMA}(1,0,2)$ & 1733.0 & -861.49 & 1752.9 & -871.44 & 8772.1 & -4382.06 & 3427.4 & -1708.7 \\
\hline $\operatorname{SARIMA}(1,0,3)$ & 1704.6 & -846.30 & 1671.9 & -839.43 & 8772.3 & -4382.67 & 3428.1 & -1709.0 \\
\hline $\operatorname{SARIMA}(1,0,4)$ & 1731.5 & -858.73 & 1700.1 & -843.02 & 8773.2 & -4382.60 & 3429.9 & -1708.93 \\
\hline $\operatorname{SARIMA}(2,0,0)$ & 1977.9 & -984.98 & 1919.2 & -955.64 & 9209.5 & -4600.75 & 3570.9 & -1781.45 \\
\hline
\end{tabular}

$\mathrm{AIC}=$ Akaike Information Criteria; Bold indicate minimum value among the models.

After that, it is compared the obtained models $\operatorname{SARIMA}(0,0,0)(1,0,3)_{12}, \operatorname{SARIMA}(0,0,0)(1,0,1)_{12}$, $\operatorname{SARIMA}(0,0,0)(1,0,2)_{12}$ and $\operatorname{SARIMA}(0,0,0)(1,0,1)_{12}$ to Single Exponential, Double Exponential and Holt Winters' Method via ME, RMSE, MAE and MASE.

Table 3. Forecasting accuracy measures under different models for different variables

\begin{tabular}{|c|c|c|c|c|c|}
\hline Variables & Models & ME & RMSE & MAE & MASE \\
\hline \multirow{4}{*}{ Maximum Temperature } & SARIMA $(0,0,0)(1,0,3)$ & 0.0706 & 0.7021 & 0.5325 & 0.7287 \\
\hline & "Single Exponential & 0.0055 & 0.6934 & 0.5272 & 0.7215 \\
\hline & Double Exponential & 0.0039 & 0.6949 & 0.5286 & 0.7235 \\
\hline & Holt Winters' Method & 0.0257 & 0.6988 & 0.5324 & 0.7287 \\
\hline \multirow{4}{*}{ Minimum Temperature } & SARIMA $(0,0,0)(1,0,1)$ & 0.0850 & 0.6737 & 0.5015 & 0.7597 \\
\hline & "Single Exponential & 0.0015 & 0.6607 & 0.4903 & 0.7428 \\
\hline & Double Exponential & 0.0185 & 0.6762 & 0.5156 & 0.7811 \\
\hline & Holt Winters' Method & 0.0297 & 0.6632 & 0.4951 & 0.7501 \\
\hline \multirow{4}{*}{ Rainfall } & SARIMA $(0,0,0)(1,0,2)$ & 4.0234 & 70.6504 & 49.4503 & 0.7121 \\
\hline & Single Exponential & 0.6158 & 70.4304 & 48.6665 & 0.7008 \\
\hline & Double Exponential & 0.6168 & 70.3358 & 48.8665 & 0.7108 \\
\hline & "Holt Winters' Method & 0.21724 & 70.2358 & 48.0516 & 0.6919 \\
\hline \multirow{4}{*}{ Humidity } & SARIMA $(0,0,0)(1,0,1)$ & 0.0723 & 2.2668 & 1.6938 & 0.8082 \\
\hline & Single Exponential & 0.0096 & 2.1092 & 1.5912 & 0.7593 \\
\hline & Double Exponential & 0.0184 & 2.1721 & 1.6239 & 0.7745 \\
\hline & ${ }^{*}$ Holt Winters' Method & 0.0074 & 2.1073 & 1.5908 & 0.7591 \\
\hline
\end{tabular}

* indicates the best model of each variable.

The table 3 shows that the Single Exponential model has lowest errors than other model both for the variable's maximum temperature and minimum temperature. The Holt-Winters' method for other two variables, rainfall and humidity appear deepest errors. 

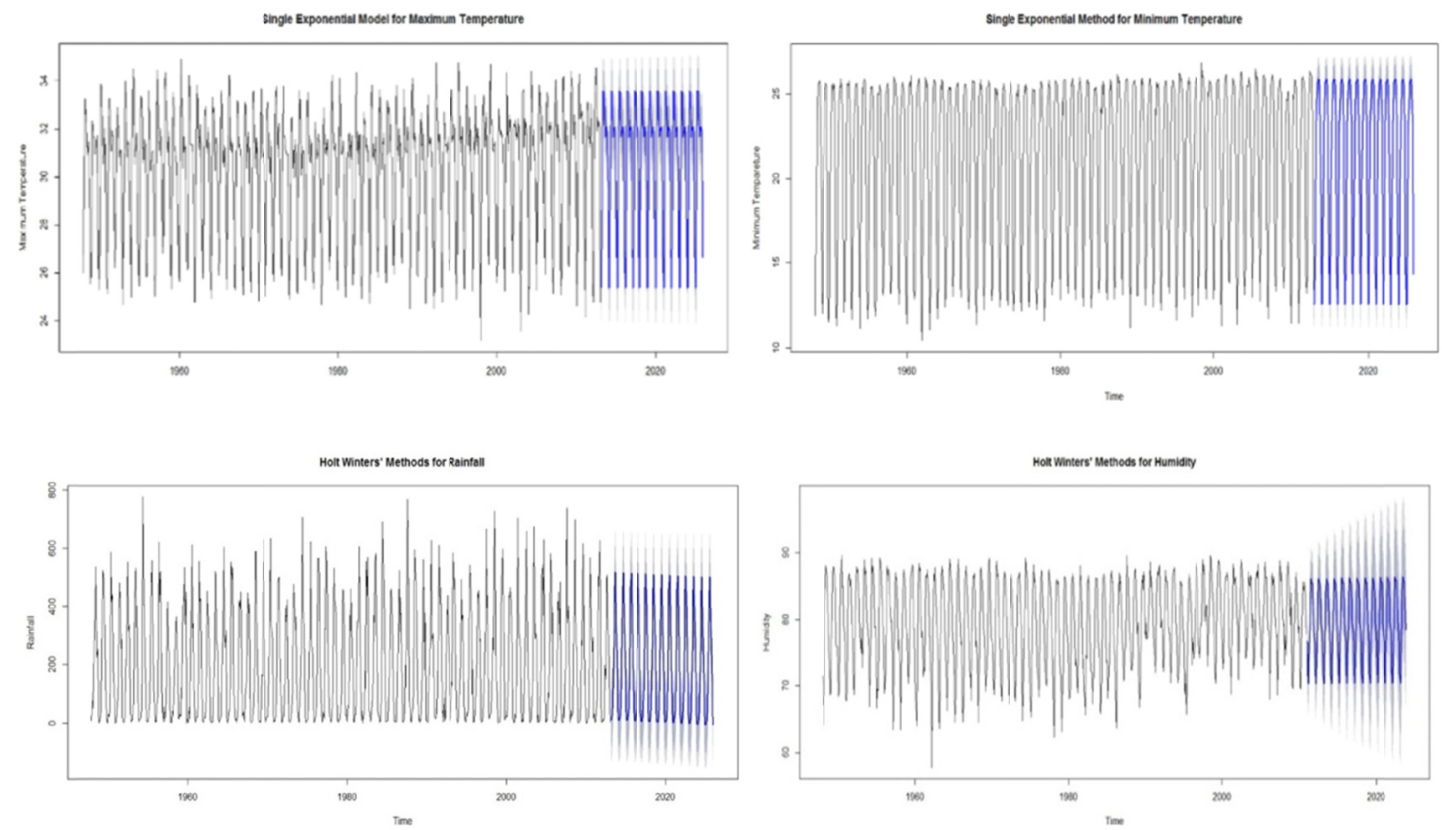

Figure 7. The forecasting of selected weather variables by their respective best model of Bangladesh

The figure 7 shows the forecasting visualization of different variables with several techniques and the blue line represents the forecasting values of the maximum and minimum temperature, humidity, rainfall from 2012 to 2025. The figures depict that the maximum average temperature will be high from April to May and its increasing slightly. Whereas, the minimum average temperature will be high in April and May and it is increasing slightly. Moreover, the average rainfall will decrease slightly in upcoming years, indicating the warming weather. Also, the humidity will be increasing slightly in those periods.

\section{Conclusions}

In this research, including time series plot, month plot and Buys Ballot plot etc. are used for identifying different elements of time series (figure 2, 3, 4, 5). After analyzing these weather components, the research discovers that these variables are seasonally affected. Moreover, Canova-Hansen analysis specifies all these weather variables are seasonally stationary (table 4). So, fitting the different seasonal time series models (SARIMA) and obtain the models SARIMA $(0,0,0)(1,0,3)_{12}, \operatorname{SARIMA}(0,0,0)(1,0,1)_{12}, \operatorname{SARIMA}(0,0,0)(1,0,2)_{12}$ and $\operatorname{SARIMA}(0,0,0)(1,0,1)_{12}$ are the best for high and low temperature, rainfall and humidity on the basis of AIC and log likelihood (figure 6 and table 2). Then, the acquired model via traditional models like single exponential, double exponential and Holt-Winters' methods models are compared for selecting the best model. The error measurement shows that traditional methods give a better result than our acquired model (table 3). Though this research discovered seasonality for the climate data, still traditional models are the best to forecast for predict future information of selected variables (figure 7).

\section{References}

Ahmed, A. U. (2006). Bangladesh Climate Change Impacts and Vulnerability. Agargaon, Dhaka-1207, Bangladesh: Climate Change Cell, Department Of Environment.

Ahmed, A. U., \& Haque, M. R. (2002). Bangladesh Climate Change Impacts and Vulnerability. Dhaka, Bangladesh: Climate Change Cell, Department of Environment.

Akaike, H. (1969). Fitting autoregressive models for prediction. Annals of the institute of Statistical Mathematics, 21 (1), 243-247.

Bangladesh Bureau of Statistics. (2014). Statistical Year Book of Bangladesh. Dhaka, Bangladesh: SID and Ministry of Planning Government of the Republic of Bangladesh.

Biswas, M. (2014). Climate Change \& its Impacts on Bangladesh. Dhaka, Bangladesh: Planned Decentralization : Aspired Development.

Chatfield, C. (2003). The Analysis of Time Series: An Introduction. Springer. 
Cleveland, W. S. (1995). Visualizing Data. Statistics in Medicine. https://doi.org/10.1002/sim.4780141212

Diaz-Emparanza, I., \& Moral, M. P. (2014). Numerical distribution functions for seasonal stability tests. Statistics and Probability Letters, 44-49. https://doi.org/10.1016/j.spl.2013.12.002

Douglas Wood, B. D. (1996). Classifying trend movements in the MSCI U.S.A. capital market index-A comparison of regression, arima and neural network methods. Computers \& Operations Research, 23, 611-622. https://doi.org/10.1016/0305-0548(95)00065-8

Fomby, T. B. (2008). Buys Ballot Plots:Graphical Methods for Detecting Seasonality in Time Series. Southern Methodist University. Dallas, TX.

George, E. P. B., Jenkins, G. M., Reinsel, G. C., \& Ljung, G. M. (2015). Time series analysis: forecasting and control. San Francisco, CA: Holden-Day.

Glahn H. R., \& Lowry, D. A. (1972). The Use of Model Output Statistics (MOS) in Objective Weather Forecasting. Journal of Applied Meterology, 11(8), 1203-1211. https://doi:10.1175/1520-0450(1972)011

Gujarati, D. N., Porter, D. C., \& Gunasekar, S. (2011). Basic Econometrics (5th ed.). New York: McGraw-Hill Companies, Inc.

Hansen, F., \& Canova, B. (1995). Are Seasonal Patterns Constant over Time? A Test for Seasonal Stability. Journal of Business \& Economic Statistics, 13(3). https://doi: 10.1080/07350015.1995.10524598

Hyndman, R. J. (2017). Forecasting: principles and practice. OTexts.

Josep Lloret, J. L. (2000). Time series modelling of landings in Northwest Mediterranean Sea. ICES Journal of Marine Science, 57(1), 171-184. https://doi.org/10.1006/jmsc.2000.0570

Khan, M. S., Islam, M., Kabir, M. R., \& Ali, L. E. (2016). A Comparative Study of Forecasting Agricultural Time Series: Some Selected Foodgrain in Bangladesh. Journal of Mechanics Continua and Mathematical Sciences., 10(2), 1500-1510.

Kibunja, H. W., Kihoro, J. M., Orwa, G. O., \& Yodah, W. O. (2014). Forecasting Precipitation Using SARIMA Model: A Case Study of Mt. Kenya Region. Mathematical Theory and Modeling, 4(11), 2224-5804.

Klein, W. H., \& Lewis. F. (1970). Computer Forecasts of Maximum and Minimum Temperatures. Journal of Applied Meteorology, 9(3), 350-359. https://doi.org/10.1175/1520-0450(1970)009<0350:CFOMAM>2.0.CO;2

Maindonald, J., \& Braun, W. J. (2010). Data Analysis and Graphics Using R: An Example-Based Approach (3 ${ }^{\text {rd }}$ ed.). Cambridge: Cambridge University Press.

Makridakis, S. G., Wheelwright,S. C., \& Hyndman, R. J. (1998). Forecasting: Methods and Applications (3 ${ }^{\text {rd }}$ ed.). John Wiley \& Sons, Inc.

Manoj Kumar, A. N. (2009). Surface flux modelling using ARIMA technique in humid subtropical monsoon area. Journal of Atmospheric and Solar-Terrestrial Physics, 71(12), 1293-1298. https://doi.org/10.1016/j.jastp.2009.05.001

Newbold, P., Carlson, W. L., \& Thorne, B. M. (2012). Statistics for Business and Economics (8th ed.). Prentice Hall.

Pankratz, A. (1983). Forecasting with Univariate Box - Jenkins Models: Concepts and Cases. New York: John Wiln\& Sons. https://doi.org/10.1002/9780470316566

Permanasari, A. E., Hidayah, I., \& Bustoni, I. A. (2013, October). SARIMA (Seasonal ARIMA) implementation on time series to forecast the number of Malaria incidence. In International Conference on Information Technology and Electrical Engineering (ICITEE), 203-207. https://doi.org/64433b3ff662ecd2f731cf5ef556d67dfedc4322

Peter, J., \& Brockwell, A. R. (2016). Introduction to Time Series and Forecasting (3rd ed.). New York, Inc: Springer-Verlag.

Tseng, F., Tzeng, G., Yu, H., \& uan, B. J. C. (1998). Fuzzy ARIMA model for forecasting the foreign exchange market. Fuzzy Sets and Systems, 118. https:// doi.org/10.1016/S0165-0114(98)00286-3

Volkan, S., \& Ediger, S. A. (2007). ARIMA forecasting of primary energy demand by fuel in Turkey. Energy Policy, 35(3), 1701-1708. https://doi.org/10.1016/j.enpol.2006.05.009

Wichern, D. W., \& Hanke, J. E. (2014). Business Forecasting (9th ed.). New Jersey: Pearson, Prentice Hall.

Wilks, S. S. (1938). The Large-Sample Distribution of the Likelihood Ratio for Testing Composite Hypotheses. 
Yusof, F., \& Kane, I. (2013). Volatility modeling of rainfall time series. Theoretical and applied climatology, 113(1-2), 247-258. https://doi.org/10.1007/s00704-012-0778-8

\section{Copyrights}

Copyright for this article is retained by the author(s), with first publication rights granted to the journal.

This is an open-access article distributed under the terms and conditions of the Creative Commons Attribution license (http://creativecommons.org/licenses/by/4.0/). 